\title{
ANALISIS K3 SEKSI CASTING DENGAN PENDEKATAN TEKNIK FTA) DAN JOB DAN JSA AGAR MEMINIMUMKAN TINGKAT RISIKO KECELAKAAN DALAM KERJA
}

\author{
Sofian Bastuti \\ Program Studi Teknik Industri, Universitas Pamulang, Tangerang Selatan, Banten
}

\begin{abstract}
ABSTRAK
PT. Surya Toto Indonesia, Tbk merupakan sebuah perushaan produsen produk peralata da perlegkapan kebutuhan Plumbing Fitting yang cukup besar di Asia Tenggara. Berbagai proses produksinya dengan mesin dan mempunyai potensi bahya dari beberapa proses salah satunya proses Casting 2 adalah proses pencetakkan atau pengecoran logam untuk membentuk desain untuk menghasilkan part dan produk fitting. Jumlah kecelakaan kerja di PT. Surya Toto Indonesia, Tbk dari Tahun 2010 sampai dengan Tahun 2016 total ada 19 kasus kecekakaan di daam pabrik. Sehingga diperlukannya untuk mengukur tingkat risiko kecelakaan kerja agar bisa menurunkan tingkat kecelakaan kerja, khususnya di seksi Casting 2 dengan pedekatan teknik Job Safety Analysis (JSA) dan Fault Tree Analysis (FTA) untuk menurunkan tingkat risiko kecelakaan kerja di PT. Surya Toto Indonesia, Tbk. Setelah dilakukan tindakan perbaikan maka nilai tingkat risiko pada pekerjaan proses memotong di mesin cutting, sebelum perbaikan adalah 450 (very hight), dan sesudah dilakukan tindakan perbaikan maka di dapat nilai risiko tersebut adalah 90 (substansial).
\end{abstract}

Kata Kunci : Keselamatan dan Kesehatan Kerja, JSA, FTA, Tingkat Risiko

membentuk desain untuk menghasilkan part dan produk fitting. Untuk menurunkan risiko

\section{PENDAHULUAN}

\section{A. Latar Beakang}

Indonesia memiliki banyak seakli perusahaan dibidang manufaktur daitara bidang manufaktur tersbeut ada yang berupa logam maupun non logam, baik itu perusahaan dalm negri maupun perusahaan luar negri yang mana menanmkan investasi di perusahaan negara indonesia. PT. Surya Toto Indonesia, Tbk adalah perusahaan bergerak dibidang manufaktur dan salah satu produsen produk perlengkapan Plumbing Fitting terbesar di Asia Tenggara. Berbagai proses produksinya menggunakan berbagai jeni mesin serta alat alat yang mempunyai segal potensi bahay pad ameisn dan alat tersbut, misalnya saja mesin

Press, Meisn Milling, Mesin Bubut Konvensional dan mesin yang lainnya. Dalam proses produksinya terdiri dari beberapa proses salah satunya proses Casting 2 adalah proses pencetakkan atau pengecoran logam untuk kecelakaan kerja maka dipilih Metode job safety analysis (JSA) dan fault tree analysis (FTA).

\section{B. Perumusan Masalah}

Atas dasar daripad aletar belakng maslah yang ada pada perusahaan ini maka dari itu berikut ditampilkan beberapa rumusan maslah pada penelitian ini :

1. Bagaimana mengukur tingkat risiko kecelakaan dalam bekerja pedekatan teknik job Safety Analysis (JSA) di seksi Casting 2 PT. Surya Toto Indonesia, Tbk.

2. Bagaimana mengaplikasikan Metode Fault Tree Analysis (FTA) untuk menurunkan tingkat risiko kecelakaan kerja di seksi Casting 2 PT. Surya Toto Indonesia, Tbk?

\section{Tujuan Penelitian}

Berdasarkan latar belakang dan rumusan masalah tersebut, tujuan dalam penelitian ini adalah sebagai berikut: 
1. Untuk mengukur tingkat risiko kecelakaan kerja di seksi Casting 2 PT. Surya Toto Indonesia, Tbk?

2. Mengaplikasikan FTA untuk menurunkan tingkat risiko kecelakaan kerja di seksi Casting 2 PT. Surya Toto Indonesia, Tbk?

\section{DASAR TEORI}

Keselamatan serta Kesehatan Kerja( K3) umumnya senantiasa berhubungan dengan kondisi terbebasnya seorang dari kejadian musibah ataupun hampir celaka. Jadi pada hakeketnya keselamatan bagaikan sesuatu pendekatan keilmuan ataupun bagaikan sesuatu pendekatan instan menekuni faktor- faktor yang menimbulkan terbentuknya musibah serta berupaya meningkatkan bermacam metode serta pendekatan buat memperkecil resiko terbentuknya musibah. Kesemlatan kerja ini adalah suatu keselamtan yang merupakan salah satu penunjang agar perusahaan mendapatkan zero accident Keselamatan Kerja ini berkaitan dengan alat alat, engine, airplane, ship perlengkapan kerja, bahan dan juga tidak lain proses pengolahan, landasan tempat kerja serta lingkungannya dan cara- cara melaksanakan pekerjaan( Sumber: Oktaviani Gadis Karnida, 2016). Penafsiran Keselamatan serta Kesehatan dalam bekerja bagi undangundang Nomor satu Tahun 1970 ayat 1 merupakan sesuatu usaha kerangka fikiri dalam menjaga keutuhan serta kesempurnaan jasmani serta rohani masyarakat pada biasanya serta pekerja pada spesialnya dan hasil karya budaya dalam rangka mengarah warga adil makmur bersumber pada pancasila.

Agar pekerja dapat merasakan dampak keselamatn maka diperlukan adanya pengenadlian atau pencegah agar tidak terjadi atau meminimalisir kecelakaan yang akan timbul, sbeenranya banyak cara dilakukan oleh perushaan agra terhidnar dari kecelakaan kerja, misalnya saj menaru papan peringatn, menyediaan alat keselamtan kerja dan kllain sbeaginya yang menunjang terjadinya keselamaan kerja.

\section{A. Analisis Risiko}

Analisis Resiko merupakan campuran antara mungkin terjalin sesuatu peristiwa/ frekuensi serta akibat dari kejadian itu dlam perihal ini cidera ataupun sakiit ( Sumber: OHSAS 18001: 2007). Analisis risiko merupakan suatu proses evaluasi risiko yang ditimbulkan dari bahaya-bahaya yang ada dan memberi pengendalian yang memadai atau sesuai atas pengendalian yang telah ada. Berdasarakan setiap kegiatan ini maka bahaya ataupun potensi bahayadapat diketahui dengan lebih jelas dan terperinci. Dalam proses melakukan analisis risiko perlu memasukan berbagai masukan informasi dan data sebagai bahan pertimbangan untuk menentukan pengendalian yang sesuai dilihat dari tingkat risiko yang telah ada, agar dapat mengetahui tungkat risiko bayaha tersebut dan sangat penting dilakukan oleh setiap perusahaan agar kegitaan produksi atau aliran proses berjalan dengan lancer tanpa adanya hambatanhambatan yang terjadi, berikut merupakan pertimbangan-pertimbangan yang harus diperhatikan:

1. Detail lokasi dimana pekerjaan dilakukan

2. Interaksi bahaya dalam proses aktifitas kerja ditempat kerja

3. Kemampuan manusia, perilaku, kompetensi, dan status kesehatan

4. Intruksi kerja, sistem kerja, izin kerja, dan kondisi lingkungan

5. Potensi kegagalan proses dari mesin-mesin Ada pula tipe- tipe tata cara analisis resiko bersumber pada OHSAS 18001: 2007 dan memikirkan usaha dalam mengendalikas sebuah resiko yang sudah dicoba, diantaranya yaitu sebagai berikut dibawah ini :

1. Analisa kualitatif

Teknik ini berguna dalam meningktkan proritas tingkat suatu risiko yang telah terlebih dahulu selesai (Sumber : AS/NZS 4360 : 1999). Tek nik ini bekerja dengan penggunaan dua parameter matriks yaitu kemugkinan dan konsekuensi. Skala ukur kemungkin dan konsekuensi atau bisa disebuty juga likelihood dan concenqunece

2. Analisa Semi- kuantitatif 
Tata cara analisis semi- kuantitatif ialah tata cara yang mengombinasikan antara angka yang bertabiat subjektif pada kemungkinan serta akibat dengan model suatu rum usan matetamtis, yang menciptakan tingkatan resiko dengan menggunakan kriteria tertentu. Teknik ini sangat bermanfaat buat mengenali serta membagikan peringkat dari sesuatu peristiwa yang berpotensi memunculkan konsekuensi yang parah. Untuk itu perlu dilakukan analisis semi kualitatif untuk medapatkan data yang lebih baik atau valid, semisal jenis rusakan alatalat, gangguan pada suatu bisnis, cidera pada mannusia dan lainlain (Kolluru, 1996). Penjelasan skala ukuran semi kuantitatif paparan (Exposure) bisa kita lihat dalam pada tabel dibawah ini:

Tabel 1 Skala Ukuran Semi

Kuantitatif Paparan (Exposure)

\begin{tabular}{|c|c|c|c|}
\hline Variabel & Uraian & Contoh rinci & Rating \\
\hline \multirow{6}{*}{$\begin{array}{c}\text { Paparan } \\
\text { (frekuensi } \\
\text { bahaya } \\
\text { terhadap } \\
\text { bahaya) }\end{array}$} & Countinously & $\begin{array}{l}\text { Terjadi secara terus } \\
\text { menerus/sering }\end{array}$ & 10 \\
\hline & Frequently & $\begin{array}{l}\text { Kira-kira satu kali } \\
\text { dalam sehari }\end{array}$ & 6 \\
\hline & Occasionally & $\begin{array}{l}\text { Sekali seminggu } \\
\text { sampai sekali sebulan }\end{array}$ & 3 \\
\hline & Infrequent & $\begin{array}{l}\text { Sekali sebulan sampai } \\
\text { sekali setahun }\end{array}$ & 2 \\
\hline & Rare & $\begin{array}{l}\text { Pernah terjadi tetapi } \\
\text { sangat jarang }\end{array}$ & 1 \\
\hline & Very rare & Tidak pernah terjadi & 0,5 \\
\hline
\end{tabular}

(Sumber : AS/NZS 4360, 2004)

Penjelasan skala ukuran semi kuantitatif konsekuensi (Consequency) dapat kita lihat pada Tabel 2.

Tabel 2 Skala Ukuran Semi Kuantitatif Konsekuensi (Consequency)

\begin{tabular}{|c|c|l|c|}
\hline Variabel & Uraian & \multicolumn{1}{|c|}{ Contoh rinci } & Rating \\
\hline \multirow{2}{*}{$\begin{array}{c}\text { Konsekuensi } \\
\text { (akibat/dampak } \\
\text { yang mungkin } \\
\text { ditimbulkan } \\
\text { dari suatu } \\
\text { kejadian) }\end{array}$} & Catastropic & $\begin{array}{l}\text { Kerusakan sangat } \\
\text { parah dengan kerugian } \\
\text { diatas \$ 1 juta, } \\
\text { terhentinya aktifitas, } \\
\text { kerusakan besar dan } \\
\text { menetap terhadap } \\
\text { lingkungan }\end{array}$ & 100 \\
\cline { 2 - 4 } & Disaster & $\begin{array}{l}\text { Kematian, kerusakan } \\
\text { setempat dan menetap } \\
\text { terhadap lingkungan, }\end{array}$ & 50 \\
\cline { 2 - 4 } & & & \\
\hline
\end{tabular}

\begin{tabular}{|c|c|c|}
\hline & $\begin{array}{l}\text { kerugian } \$ 500.000-\$ \\
2.000 .000\end{array}$ & \\
\hline $\begin{array}{c}\text { Very } \\
\text { serious }\end{array}$ & $\begin{array}{l}\text { Cacat/penyakit } \\
\text { menetap, kerusakan } \\
\text { sementara terhadap } \\
\text { lingkungan, kerugian } \\
\$ 50.000-\$ 500.000\end{array}$ & 25 \\
\hline Serious & $\begin{array}{l}\text { Cidera/penyakit yang } \\
\text { serius tetapi } \\
\text { sementara, efek yang } \\
\text { merugikan terhadap } \\
\text { lingkungan, kerugian } \\
\$ \\
5.000-\$ 50.000\end{array}$ & 15 \\
\hline Important & $\begin{array}{l}\text { Membutuhkan } \\
\text { penanganan medis, } \\
\text { kerugian } \$ 500-\$ \\
5.000 \text {, dapat dirasakan } \\
\text { tapi tidak merugikan }\end{array}$ & 5 \\
\hline Noticeable & $\begin{array}{l}\text { Luka ringan, memar } \\
\text { atau penyakit ringan, } \\
\text { kerusakan kecil } \\
\text { dengan kerugian } \\
\text { produksi sebesar }<\$ \\
500\end{array}$ & 1 \\
\hline
\end{tabular}

(Sumber : AS/NZS 4360, 2004)

Penjelasan skala ukuran semi kuantitatif kemungkinan (Likelihood) bisa kita lihat dalam pada tabel dibawah ini:

Tabel 3 Skala Ukuran Semi Kuantitatif Kemungkinan (Likelihood)

\begin{tabular}{|c|c|c|c|}
\hline Variabel & Uraian & Contoh rinci & Rating \\
\hline \multirow{6}{*}{$\begin{array}{c}\text { Likelihood } \\
\text { (kecenderungan } \\
\text { konsekuensi } \\
\text { akibat suatu } \\
\text { kejadian) }\end{array}$} & $\begin{array}{l}\text { Almost } \\
\text { Certain }\end{array}$ & $\begin{array}{l}\text { Akibat yang paling mungkin } \\
\text { timbul apabila kejadian tersebut } \\
\text { tejadi }\end{array}$ & 10 \\
\hline & Likely & Kemungkinan 50:50 & 6 \\
\hline & Unusual & Mungkin terjadi tetapi jarang & 3 \\
\hline & $\begin{array}{c}\text { Romately } \\
\text { possible }\end{array}$ & $\begin{array}{l}\text { Akibat tersebut bukan akibat } \\
\text { langsung, melainkan akibat tidak } \\
\text { langsung }\end{array}$ & 1 \\
\hline & Conceivable & $\begin{array}{l}\text { Mungkin terjadi, tetapi tidak } \\
\text { pernah terjadi meskipun dengan } \\
\text { paparan selama bertahun-tahun }\end{array}$ & 0,5 \\
\hline & $\begin{array}{l}\text { Practically } \\
\text { impossible }\end{array}$ & Tidak mungkin terjadi & 0,1 \\
\hline
\end{tabular}


III. METODE DAN TEKNIK PENGUKURAN A. Metode Analisis Data

Dari tabel diata s langkah selantjutnya yaitu mengidentifikas dan kemudian mententukan tingkat resiko yang kan timbul ataupun muncul pada jenis kegiatan pekerjaan tersebut agra dilihat man apotensi tingkatt resiko yang memungkinkan paling berbahaya. Penentuan tingkat risiko merupakan tahapan terkahir pada proses analisis risiko, perkiraan tingkat risiko akan membantu dalam pengambilan keputusan untuk menanggulangi risiko yang ada. Tingkat risiko pada analisis semi kuantitatif yaitu berdasarakan dari hasil perkalian dari nilai variabkle yang didapatakankemungkinan paparan, serta konsekuaensi dari berbagai resiko yang mungkin timbul. Pada tahapan tahapan pengerhajaan suatu kegiatan proses produksi. Adapun untuk mennetukan sejauh mana level dari resiko yang akan terjadi secara teknik semi kuantitatif mka dapat duigunakan Fine Chart dengan nilai berupa skor mengacu pada metode yang ditemukan oleh W.T Fine pada tahun

1971. Seperti pada Tabel 4. Dibawah ini

Tabel 4 Tingkat Risiko Semi Kualitatif

\begin{tabular}{|c|c|lr|}
\hline $\begin{array}{c}\text { Tingkat } \\
\text { Risiko }\end{array}$ & Kategori & \multicolumn{2}{|c|}{ Tindakan } \\
\hline$>350$ & Very High & $\begin{array}{l}\text { Aktifitas dihentikan } \\
\text { sampai risiko bisa } \\
\text { dikurangi ringga } \\
\text { mencapai batas yang } \\
\text { diperbolehkan atau } \\
\text { diterima }\end{array}$ \\
\hline $180-350$ & Prority 1 & $\begin{array}{l}\text { Perlu pengendalian } \\
\text { mungkin sesegera }\end{array}$ \\
\hline $70-180$ & Substansial & $\begin{array}{l}\text { Mengharuskan adanya } \\
\text { perbaikan secara teknis }\end{array}$ \\
\hline $20-70$ & Priority 3 & $\begin{array}{l}\text { Perlu diawasi dan } \\
\text { diperhatikan secara } \\
\text { berkesinambungan }\end{array}$ \\
\hline$<20$ & Acceptable & $\begin{array}{l}\text { Intensitas yang } \\
\text { menimbulkan risiko } \\
\text { dikurangi seminimal } \\
\text { mungkin }\end{array}$ \\
\hline
\end{tabular}

(Sumber : AS/NZS 4360, 2004)
Teknik pengumpulan data pada riset ini menggunakan data kuantitatif dan data kualitatif. ini sebgai berikut : a. Data

Kecelakaan Kerja

b. Data Jam Kerja Hilang

c. Total Jam Kerja

2. Data Kualitatif Adapun dat ini sebgai berikut : a.Latar belakang Perusahaan

b.Flow Organisasi, Tugas dan Tanggung jawabnya

Adapun penggunaan jenis data yang digunakan pada penelitain ini beruppa data kuantitatif danjug data kualitattif dapat di jelaskan pada poin poin dibawah ini:

1. Data Kuantitatif

Data Kuantitatif yaitu data yang berupa angka-angka yang dapat dihitung atau diukur secara matematis. Data kuantitatif dalam penulisan penelitian ini terdiri dari:
a. Data Kecelakaan Kerja
b. Data Jam Kerja Hilang
c. Total Jam Kerja

2. Data Kualitatif

Data Kualitatif yaitu data yang tidak dapat dihitung atau diukur secara matematis. Data kualitatif dalam penulisan ini terdiri dari: a. Sejarah Perusahaan

b. Struktur Organisasi, Tugas dan Tanggung jawabnya

Adapun Sumber data pada jenis suatu kegiatan riset ini didapatkan dengan cara salah satu sumber data yang berupa data sekunder, data sekunder ini biasanya dapat didapatakan dario data perusahaan. Data ini merupakan pengumpulan yang secara tidak langsung terjun pengambilnnya dari sumber Data sekunder ini diperoleh dari pihak intern perusahaan yang berupa dokumen atau berkas yang ada seperti:

1. Latar Belakang Perusahaan

2. Struktur Orgnanisasi

3. Data Kecelakaan Kerja

Data-data yang berhasil dikumpulkan selanjutnya dilakukan pengolahan, guna mencari solusi dari permasalahan yang
1. Data Kuantitatif Adapun dat 
dihadapi. Adapun dalam pengolahan data ini, terdiri dari atas beberapa tahap yaitu:

1. Perhitungan Statistik Kecelakaan Kerja:

a.Metode Frequency Rate

b. Metode Severity Rate

c.Metode Safety Score

2. Tahapan Pembuatan Job Safety Analysis (JSA):

a.Memilih tipe setiap pekerjaan

b. Membuat Tim Analisis

Keselamatan kerja

c.Medeskripsikan uraian pekerjaan

d. Menguraikan identifikasi suatu potensi

bahaya

e.Mengerjkakan Penyelesaian akhir 3.

Perhitungan Risk Assessment:

Likelihood x Esposure x Consequence 4.

Tahapan Pembuatan Fault Tree Analysis (FTA):

a. Mengidentifikasi kecelakaan kerja

b. Mempelajari sistem kerja

c. Mengembangkan pohon kesalahan

\section{HASIL DAN PEMBAHASAN}

\section{A. Menghitung statistik kecelakaan kerja}

Berikut akan dijelsakna bagaimna cara mennghitung statsitik kecelakan kerja yang terjadi pad akegiatan proses, sebagi berikuit dibawah ini :

1. Metode Frequency Rate (FR) Menghitung nilai Frequency Rate dengan Rumus:

$\mathrm{FR}=\frac{\text { Banyak kecelakaan kerja } \mathrm{x} 1.000 .000}{\text { Total jam kerja manusia }}$

Rekapitulasi perhitungan frequency rate seperti pada Tabel 5.

Tabel 5 Rekapitulasi Perhitungan Frequency

Rate

\begin{tabular}{|c|c|c|c|c|}
\hline $\begin{array}{c}\text { Tahu } \\
\mathbf{n}\end{array}$ & $\begin{array}{c}\text { Total } \\
\text { Kecelakaa } \\
\mathbf{n}\end{array}$ & $\begin{array}{c}\text { Jam } \\
\text { Kerja } \\
\text { Manusia }\end{array}$ & $\begin{array}{c}\text { Nilai } \\
\text { Frequenc } \\
\boldsymbol{y} \\
\text { Rate }\end{array}$ & $\begin{array}{c}\text { Kecelakaa } \\
\text { n Per } \\
\text { Tahun }\end{array}$ \\
\hline 2010 & 5 & $\begin{array}{c}2.030 .25 \\
9\end{array}$ & 2,47 & 2 \\
\hline 2011 & 3 & $\begin{array}{c}2.257 .73 \\
8\end{array}$ & 1,32 & 1 \\
\hline 2012 & 4 & $\begin{array}{c}2.441 .47 \\
4\end{array}$ & 2 & 2 \\
\hline
\end{tabular}

\begin{tabular}{|c|c|c|c|c|}
\hline 2013 & 1 & $\begin{array}{c}2.359 .58 \\
3\end{array}$ & 0 & 0 \\
\hline 2014 & 3 & $\begin{array}{c}2.487 .04 \\
4\end{array}$ & 1 & 1 \\
\hline 2015 & 4 & $\begin{array}{c}2.687 .18 \\
9\end{array}$ & 1 & 1 \\
\hline 2016 & 0 & 0 & 0 & 0 \\
\hline
\end{tabular}

(Sumber: Pengolahan dari Berbagai Sumber)

Contoh mencari nilai frequency rate pada

Tabel 5.

a. Total Kecelakaan Tahun $2010=5$

Kecelakaan

b. Jam Kerja Manusia = 2.030.259 Jam

$\mathrm{FR}=\frac{5 \times 1.000 .000}{2.030 .259}=2.47=$ Kecelakaan $/$ Tahun

2. Metode Severity Rate (SR) Menghitung nilai Severity Rate dengan Rumus :

$\mathrm{SR}=\frac{\text { Hilang jam kerja } \times 1.000 .000}{\text { Total jam kerja manusia }}$

Rekapitulasi Perhitungan Severity

Rate seperti pada Tabel 6.

Tabel 6 Rekapan data SR dapat dilihat dari gambar tabel dibawah ini :

\begin{tabular}{|c|c|c|c|c|}
\hline Tahun & $\begin{array}{c}\text { Hari } \\
\text { Yang } \\
\text { Hilang }\end{array}$ & Jam Kerja & $\begin{array}{c}\text { Nilai Severity } \\
\text { Rate }\end{array}$ & $\begin{array}{c}\text { Lost Day Cause } \\
\text { Accident / Year }\end{array}$ \\
\hline 2010 & 11,5 & 2.030 .259 & 5,66 & 5 \\
\hline 2011 & 7 & 2.257 .738 & 3,10 & 3 \\
\hline 2012 & 2 & 2.441 .474 & 0,81 & 1 \\
\hline 2013 & 0 & 2.359 .583 & 0 & 0 \\
\hline 2014 & 1 & 2.487 .044 & 0,40 & 0 \\
\hline 2015 & 0 & 2.687 .189 & 0 & 0 \\
\hline 2016 & 0 & 0 & 0 & 0 \\
\hline
\end{tabular}

Sumber: (Pengolahan dari Berbagai Sumber)

Keterangan:

Untuk mencari hari yang hilang yaitu : jam kerja hilang: waktu jam kerja (8 Jam) Contoh mencari nilai Severity Rate pada

Tabel 6.

a. Hilang Hari Kerja Tahun $2010=$ 11,5

Hari

b. Jam Kerja Manusia $=2.030 .259$ Jam

SR $=\frac{11,5 \times 1.000 .000}{2.030 .259}=5,66=5$ Lost day accident

3. Teknik Safety Score (STS) 
Untyuk mengetahui bagimna itu Pada Umummnya maka Safety Score positif menunjukkan keadaan yang tidak baik dalam arti buruk, dan begitu juga balikannya krtika angka Safety Score negatif menunjukkan keadaan membaik. Berikut menghitung nilai Safety Score dengan Rumus:

STS $=\frac{-}{\text { FR Lampau }} \underset{\text { Lampau }}{\text { FR }} \quad$ FR

Rekapitulasi Perhitungan Safety Score seperti pada Tabel 7.

Tabel 7. Rekapitulasi Perhitungan Safety

\begin{tabular}{|c|c|c|c|c|}
\hline \multicolumn{7}{|c|}{ Score } \\
\hline Tahun & Fr Sekarang & Fr Lampau & $\begin{array}{c}\text { Nilai Safety } \\
\text { Score }\end{array}$ & Keterangan \\
\hline 2010 & 2 & - & - & - \\
\hline 2011 & 1 & 2 & $-0,5$ & Baik \\
\hline 2012 & 2 & 1 & 1 & Buruk \\
\hline 2013 & 0 & 2 & -1 & Baik \\
\hline 2014 & 1 & 0 & 0 & Buruk \\
\hline 2015 & 1 & 1 & 0 & Buruk \\
\hline 2016 & 0 & 1 & -1 & Baik \\
\hline
\end{tabular}

(Sumber: Pengolahan dari Berbagai Sumber)

Contoh mencari nilai Severity Score pada Tabel 7.

a. Frequency Rate sekarang Tahun $2011=1$

Kecelakaan/Tahun

b. Frequency Rate sebelumnya (Tahun 2010) $=2$ Kecelakaan/Tahun STS $=\frac{1-2}{2}=-0.5$ Safety Score (Baik)

Tabel 8: Risk Assessmemt Seksi Casting 2

\begin{tabular}{|c|c|c|c|c|c|c|c|c|}
\hline \multicolumn{5}{|c|}{ IDENTIFIKASI POTENSI BAHAYA } & \multicolumn{4}{|c|}{ PENILAIAN RISIKO } \\
\hline No & $\begin{array}{c}\text { Jenis } \\
\text { Pekerjaan }\end{array}$ & $\begin{array}{c}\text { Uraian } \\
\text { Kerja }\end{array}$ & $\begin{array}{l}\text { Potensi } \\
\text { Bahaya }\end{array}$ & $\begin{array}{c}\text { Dampak } \\
\text { Risiko } \\
\text { Bahaya }\end{array}$ & 홍 & 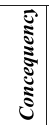 & $\begin{array}{c}\text { Nilai } \\
\text { Risiko } \\
\text { L x E x } \\
\text { C }\end{array}$ & Risiko \\
\hline 1 & Produksi & $\begin{array}{l}\text { Proses } \\
\text { memoto } \\
\text { ng }\end{array}$ & $\begin{array}{l}\text { Tangan } \\
\text { terkena } \\
\text { putaran } \\
\text { gergaji }\end{array}$ & $\begin{array}{l}\text { Cidera } \\
\text { tangan }\end{array}$ & \begin{tabular}{l|l|l}
3 & 6
\end{tabular} & 25 & 450 & Very \\
\hline
\end{tabular}

(Sumber: Pengolahan dari Berbagai Sumber)

Keterangan:

1. Dasar pengisian untuk menentukan kategori Tingkat Risiko harus berdasarkan Tingkat Risiko terbanyak atau yang mendominasi. 2. Apabila terdapat kesamaan nilai Tingkat Risiko maka yang diambil adalah Tingkat Risiko dengan nilai yang tertinggi.

3. Dari hasil perhitungan Risk Assessment di dapat level risiko tertinggi yaitu pada saat jenis pekerjaan Cutting pada proses memotong benda kerja dengan potensi bahaya tangan terkena putaran gergaji dengan nilai risiko 450 dan tingakt risiko very hight.

\section{B. Analisa Fault Tree Analysis (FTA)}

Selanjutnya dilakukan analisa perbaikan dengan teknik FTA yang dapat dilihat pada gambar dibawha ini Gambar 1.

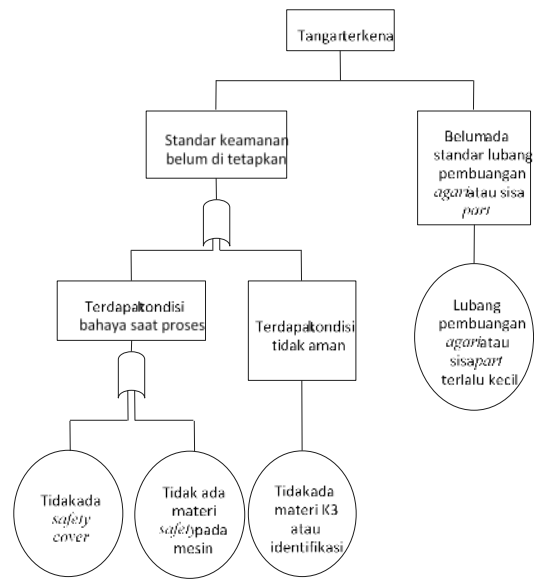

(Sumber: Pengolahan dari Berbagai Sumber)

Gambar 1. Analisa Pohon Kesalahan Tangan Terkena Putaran Gergaji

Dari hasil analisa pohon kesalahan di dapat 4 lingkaran atau peristiwa dasar potensi bahaya yaitu tangan terkena putaran gergaji sebagai berikut:

1. Tidak ada cover.

2. Tidak ada materi safety talk pada mesin cutting.

3. Tidak ada meteri K3 atau identifikasi bahaya mesin cutting.

4. Lubang pembuangan agari atau sisa part terlalu kecil.

\section{Tindakan Perbaikan FTA}

Selanjutnya pada 4 lingkaran peristiwa dasar pada Metode Fault Tree Analysis (FTA) maka dilakukan tindakan perbaikan sebagai berikut: 
1. Membuat safety cover mata gergaji yang bertujuan untuk menghindari tangan tersentuh dengan mata gergaji seperti pada Gambar 2.

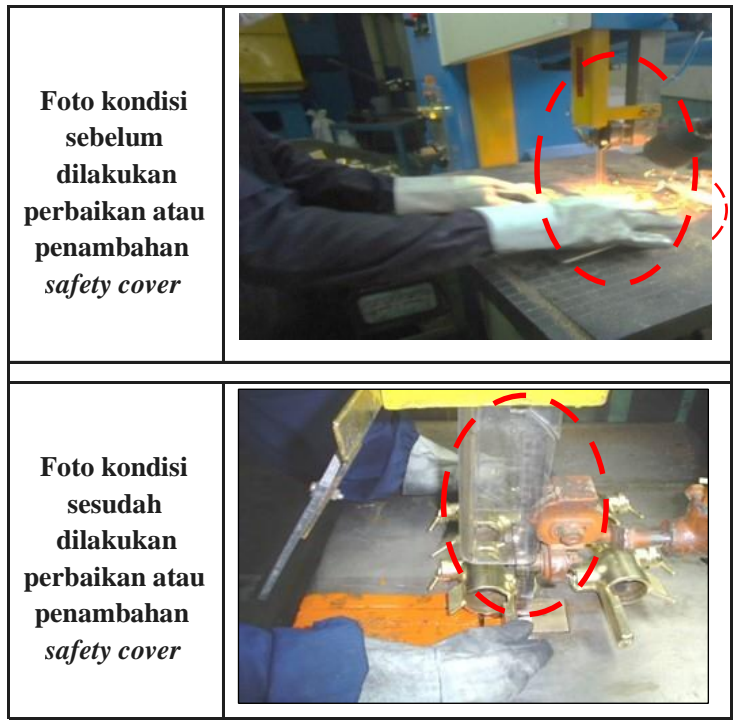

(Sumber: PT. Surya Toto Indonesia, Tbk. 2017) Gambar 2 Safety Cover

2. Membuat materi safety talk yang bertujuan untuk mengingatkan kepada karyawan cara aman proses cutting dan disampaikan pada meeting pagi sebelum kerja seperti pada Gambar 3.

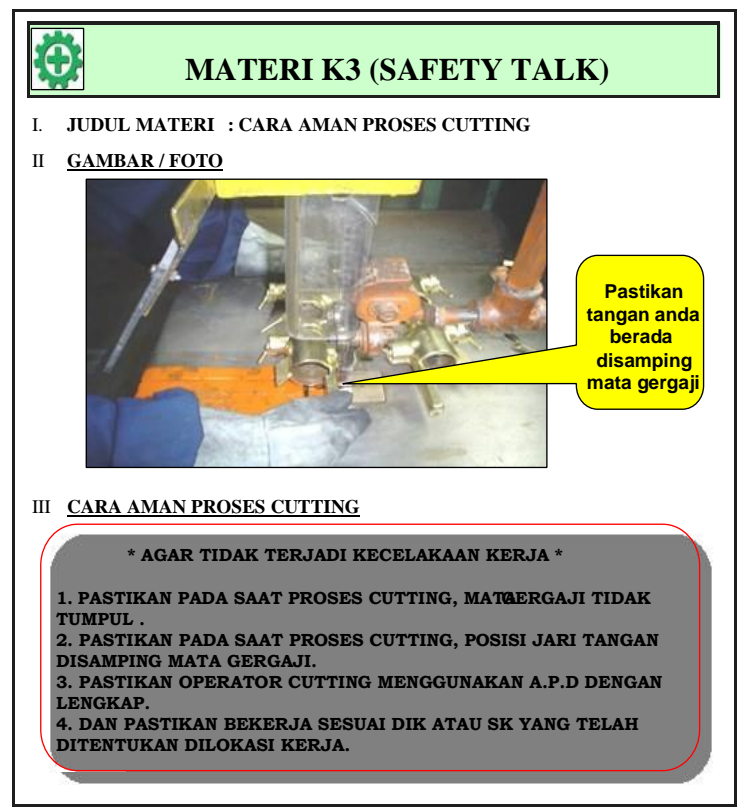

(Sumber: PT. Surya Toto Indonesia, Tbk. 2017)

\section{Gambar 3 Materi Safety Talk}

3. Membuat materi pendidikan K3 pada mesin Cutting yang bertujuan untuk pembelajaran karyawan saat akan proses pada mesin tersebut akan melihat identifikasi bahaya pada mesin Cutting dan standar alat 149 pelindung diri yang diperlukan seperti pada Gambar 4.

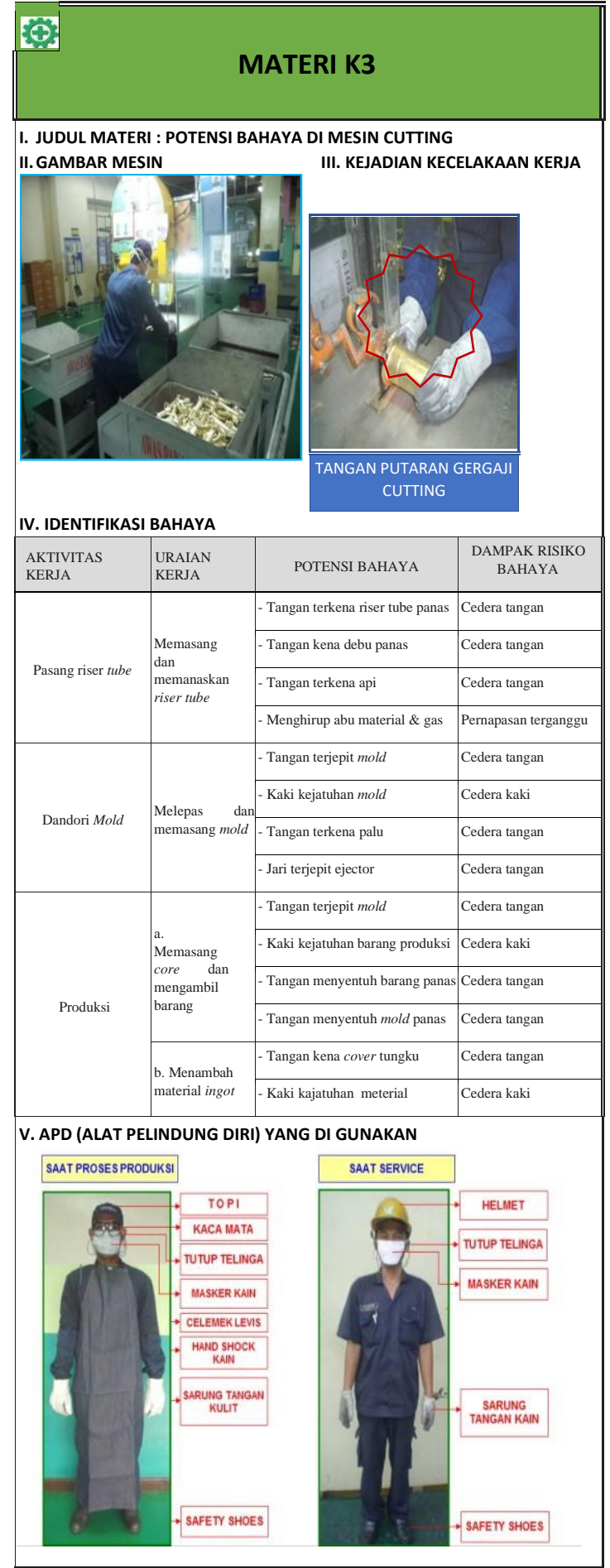

(Sumber: PT. Surya Toto Indonesia, Tbk. 2017)

\section{Gambar 4. Materi K3 Mesin Cutting}

4. Memperbaiki atau modifikasi lubang pembuangan agari dibuat lebih besar untuk memudahkan saat pembuangan sisa part seperti pada Gambar 5. 


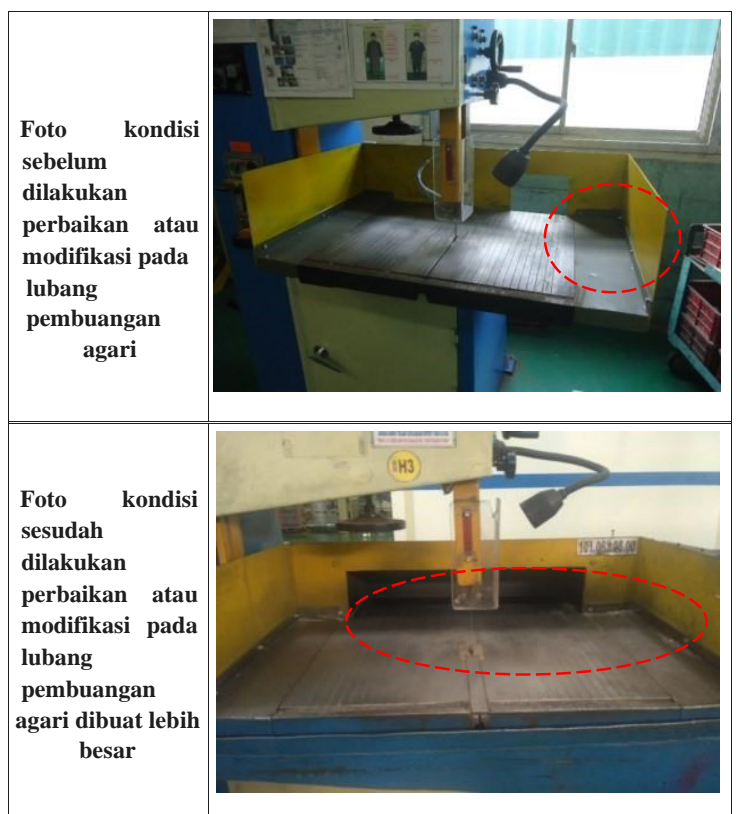

(Sumber: PT. Surya Toto Indonesia, Tbk. 2017)

Gambar 5. Modifikasi Lubang Pembuangan Agari

\section{Hasil Penilaian tingkat risiko Setelah Perbaikan}

Setelah dilakukan perbaikan di mesin cutting maka dilakukan penilaian kembali untuk tingkat risiko tertinggi seperti pada Tabel 9.

Tabel 9. Risk Assessment Setelah Perbaikan

\begin{tabular}{|c|c|c|c|c|c|c|c|}
\hline \multicolumn{8}{|c|}{ Pada Mesin Cutting } \\
\hline \multicolumn{4}{|c|}{ PENILAIAN RISIKO } & \multicolumn{4}{|c|}{$\begin{array}{c}\text { PENILAIAN RISIKO } \\
\text { SETELAH } \\
\text { PERBAIKAN }\end{array}$} \\
\hline 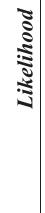 & & $\begin{array}{l}\text { Nilai } \\
\text { Risiko } \\
\text { L x E x } \\
\text { C }\end{array}$ & $\begin{array}{l}\text { Tingkat } \\
\text { Risiko }\end{array}$ & & | & $\begin{array}{l}\text { Nilai } \\
\text { Risiko } \\
\text { L x E x } \\
\text { C }\end{array}$ & $\begin{array}{c}\text { Tingkat } \\
\text { Risiko }\end{array}$ \\
\hline 3 & 62 & 450 & $\begin{array}{l}\text { Very } \\
\text { hight }\end{array}$ & \begin{tabular}{l|l}
3 & 6
\end{tabular} & 5 & 90 & Substansia \\
\hline \multicolumn{4}{|c|}{$\begin{array}{l}\text { Sebelum Perbaikan }=\text { Very } \\
\text { Hight }\end{array}$} & \multicolumn{4}{|c|}{$\begin{array}{l}\text { Seteah Perbaikan }= \\
\text { Substansial }\end{array}$} \\
\hline
\end{tabular}

(Sumber: Pengolahan dari Berbagai Sumber)

Berdasarkan Tabel 4.6 nilai tingkat risiko pada pekerjaan proses memotong di mesin cutting sebelum perbaikan adalah 450150 (very hight), dan setelah dilakukan tindakan perbaikan maka di dapat nilai risiko tersebut adalah 90 (substansial).

\section{KESIMPULAN DAN SARAN}

\section{A. Kesimpulan}

1. Berdasarkan hasil riset yang dilakukan dengan penelti lakukan dan hasil uraian yang telah dibahas, maka dapat ditarik kesimpulan bahwa.Tingkat risiko kecelakaan kerja di seksi casting PT. Surya Toto Indonesia, Tbk. adalah Mesin Core tingkat risiko Acceptable total 1 dengan nilai 10, Substansial total 13 dengan nilai 90-150. Mesin LPDC tingkat risiko Priority 3 total 3 dengan nilai 30 , Substansial total 12 dengan nilai 90-150. Mesin Shotblast tingkat risiko Priority 3 total 5 dengan nilai 30, Substansial total 4 dengan nilai 90-150. Mesin Cutting tingkat risiko Substansial total 8 dengan nilai 90, Verry Hight total 1 dengan nilai 450. Mesin Grinding tingkat risiko Priority 3 total 1 dengan nilai 25, Substansial total 12 dengan nilai 90. Berdasarkan penilaian tingkat risiko di seksi Casting 2 di dapat nilai risiko tertinggi yaitu pada pekerjaan proses memotong di mesin cutting dengan nilai risiko 450 (very hight).

2. Setelah mengaplikasikan Metode FTA maka dilakukan tindakan perbaikan untuk menurunkan nilai tingkat risiko tertinggi adalah membuat safety cover, membuat materi safety talk, membuat materi pendidikan k3 pada mesin cutting, memperbaiki atau modifikasi lubang pembuangan agari dibuat lebih besar. Setelah dilakukan tindakan perbaikan maka nilai tingkat risiko pada pekerjaan proses memotong di mesin cutting, sebelum perbaikan adalah 450 (very hight), dan sesudah dilakukan tindakan perbaikan maka di dapat nilai risiko tersebut adalah 90 (substansial).

\section{B. Saran}

Bedasarkan dari hasil riset ini dan kesimpulan yang telah uraikan oleh peneliti

maka peneliti menyarankan perlu dibujatanya pengontrolan dan pemberioan 
arahan yang dsngst terpantau oleh perusahaan mengenai bagaimana pemakaian alat perlindungan diri pada waktu mengoperasikan mesin terutama pada mesin cutting. Agra setipa kecelkaan suatu pekerjaan dapat di antisipasi dan di minimalkan seminimum mungkin.

\section{DAFTAR PUSTAKA}

Alfatiyah, R. (2017). Analisis manajemen risiko keselamatan dan kesehatan kerja dengan menggunakan metode HIRARC pada pekerjaan seksi casting. SINTEK JURNAL: Jurnal Ilmiah Teknik Mesin, 11(2), 88-101.

Alfatiyah, R., Bastuti, S., \& Prasetiyo, T. T. (2017, December). ANALISIS PENGARUH LINGKUNGAN KERJA SERTA JAMINAN SOSIAL TERHADAP KESELAMATAN DAN KESEHATAN KERJA (K3) DENGAN METODE REGRESI LINEAR BERGANDA PADA PT. DELTA CITRA MANDIRI. In PROCEEDINGS (Vol. 2, No. 1).

Anizar. (2009). Teknik Keselamatan dan Kesehatan Kerja di Industri. Yogyakarta: Graha Ilmu

Australian Standard/New Zealand Standard 4360 1999. Handbook of Risk
Management Guildelines

Bastuti, S. (2017). Keselamatan Kerja.

\begin{tabular}{|c|c|}
\hline Bastuti, & 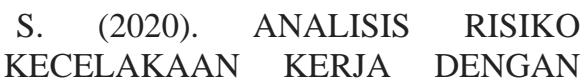 \\
\hline & METODE FAILURE MODE AND \\
\hline & EFFECT ANALYSIS (FMEA) DAN \\
\hline & TREE ANALYSIS \\
\hline & UNTUK MENURUNKAN TINGKAT \\
\hline & RISIKO KECELAKAAN KERJA (PT \\
\hline & BERKAH \\
\hline & $\begin{array}{l}\text { TEKNOLOGI: Jurnal Ilmiah dan } \\
\text { Teknologi,2(1), 48-52. }\end{array}$ \\
\hline
\end{tabular}

Candra, A. (2019). Pengendalian Persediaan Material Pada Produksi Hot Mix Dengan Pendekatan Metode Economic Order Quantity (Eoq). Jitmi (Jurnal Ilmiah Teknik Dan Manajemen Industri), 1(2), 145-153.
Cross, J. (1998). Risk Management. Dalam Study Notes SESC921. Departement of Safety Science University of New South Wales

Harrianto, Ridwan. (2008). Buku Ajar Kesehatan Kerja. Jakarta: EGC

Harrington, JM. FS. Gill. (2005). Buku Saku Kesehatan Kerja Edisi 3. Jakarta: EGC.

Infodatin. (2015). Situasi Kesehatan Kerja. Jakarta: Kementrian Kesehatan RI.

Ramli, S. (2010). Pedoman Praktis Manajemen Risiko Dalam Perspektif K3 OHS Risk Management. Jakarta: PT. Dian Rakyat

Ramli, S. (2010). Sistem Manajemen Keselamatan dan Kesehatan Kerja OHSAS 18001. Jakarta: PT. Dian Rakyat

Utaminingsih, S., \& Candra, A. (2015). Penentuan Lama Waktu Istirahat Berdasarkan Beban Kerja Dengan Menggunakan Pendekatan Fisiologis Disaint JOHN'S SCHOOL BSD. Teknologi, Jurnal Ilmiah dan teknologi, Fakultas Teknik Dan Fakultas MIPA Universitas Pamulang, 11(29), 112. 